\title{
Architects need Environmental feedback
}

Overall word count (including endnotes) 6515 words.

Figures at the end. 


\section{Abstract}

For the last 40 years, research on post occupancy evaluation has shown that often designers' intentions are not realized in their occupied buildings.

This paper examines environmental feedback within architects' offices as a fundamental ingredient of sustainability. It looks, from the architect's perspective, at the whole building process from early key design decisions to occupation by means of a feedback exercise on three case study buildings, a museum and two offices. Results show that sometimes design decisions are taken for aesthetic reasons without certainty on their environmental impact. The buildings present highly regarded design images but their environmental performance can be bettered. Improvements are possible with regards to energy consumption, glare, usability of controls, communication of strategies and comfort conditions. The architects consider the feedback lessons relevant for their work and quote future briefs and understanding how sustainable their buildings are, as main reasons for carrying out feedback.

A systematic approach to project feedback is proposed with emphasis in feeding forward to new projects and recording decision-making. For confidence in delivering sustainable designs, environmental expertise is recommended throughout any project development. In order to close the information loop, briefs need to explicitly mention targets for energy use, management expectations, control requirements and promote feedback itself.

Keywords: feedback, post occupancy evaluation, environmental performance, energy consumption, usability, comfort, sustainability, feed-forward 


\section{Introduction}

This paper tests the premise that environmental feedback is needed in current architecture practice in order to achieve sustainable buildings that seriously fulfil their claims on both energy efficiency and the provision of adequate environments for the functions they house.

It looks at the process of feedback within an architecture practice, by means of case studies, and links it back to the whole design process.

A change in attitude to feedback in architecture is required.

Architects rarely get involved in their projects after completion, the point when buildings start their operational lives. Their prior knowledge of the original intentions seems an invaluable source when it comes to judge how successful a building has been.

Historically, a slow design process allowed for innovations to develop at a similar pace and feedback occurred naturally. Nowadays, feedback has become dissociated from the system due to pressures of much faster building design and construction, with the architect's attention remaining on urgent live design projects.

The use of new materials, building techniques and "innovative" design strategies, require some measure of their success in practice. Otherwise, they constitute theoretical myths, unsupported by results in use. The environmental impact of most buildings is not assessed after occupation. And even when predictions are made in the design stages, they are not necessarily checked later on for corroboration of results, and improvement is thus stalled. 
This study considers the totality of the building process from early design decisions to commissioning, occupation and feedback into new projects with the help of case studies. Figure 1 represents schematically the stages of the overall process from which information was gathered, in order to obtain as complete a picture of the building as possible.

This paper first reviews the precedent on post occupancy evaluation and then looks at three case study buildings, explaining briefly the methodology followed, the environmental feedback results and lessons drawn. It then focuses on how relevant the architects found these feedback lessons for future projects and tries to establish a feeding forward system for practical use. The paper then concludes that a systematic approach to feedback in architectural practice is urgently required.

\section{Precedent}

The special issue of Building Research and Information (BRI, 2001) and subsequent BRI Forum articles (BRI, 2001a, 2001b, 2002), reviewed the background of Post Occupancy Evaluation (POE) in the UK, including the Postoccupancy Review of Buildings and their Engineering (PROBE) series published in the Building Services Journal (BSJ).

Since 1995, PROBE has reviewed more than twenty buildings in use. In each case, the buildings' design merits had previously been reviewed by the BSJ. The PROBE studies aimed to include a cross section of buildings, technologies and designers. However, they have not included in its sample speculative buildings, such as the two of the case studies in this paper, due to logistics difficulties in obtaining permissions from both owners and tenants (Cohen et al 2001). 
Environmentally, there seems to be no secret recipe for providing comfortable conditions within buildings. The top scoring PROBE buildings in terms of comfort include all three strategies: naturally ventilated (NV), air conditioned (AC) and mixed mode (MM) buildings (Bordass et al 2001). But there is no perfect building, as Leaman and Bordass (2001) put it: "it is unrealistic to expect everything to work well everywhere, all the time". They advocate a 'satisficing' philosophy whereby the means are provided for good enough conditions to be experienced by allowing occupants some degree of control to alleviate and minimise discomfort.

Reviewing the implications of the PROBE studies, Bordass et al (2001) emphasize the need for questioning any preconceptions and assumptions any member of the team might have about the project, in order to improve communications and achieve a building well matched to the users' expectations.

Whyte and Gann (2001) suggest that POE should develop to offer an evolutionary approach capable of taking long term changes into account and analysing the consequences for building developers, designers, owners and users. The basis of such a dynamic system should be a wide body of knowledge about the quality and value of design, including building performance.

Despite the editorial success of the PROBE studies in improving the knowledge base of the engineering community, the team recognises that feedback is still missing at all levels, and few architectural or engineering design practices consistently collect information on whether or not their buildings work (Bordass et al 2001). 
So, why is feedback and POE so elusive? What are the perceived barriers for feedback to take place effectively? Are the knowledge benefits not sufficient?

Jaunzens et al (2001) found four main possible barriers: uncertainty in funding responsibility if clients are unwilling to pay for it, perceived low value of the benefits gained, the breakdown of relationships as the project comes to an end, and finally the designers' possible liability for any problems encountered whilst carrying out POEs.

Cooper (2001) questions not only who is responsible for commissioning POE studies, but also who is professionally responsible for undertaking them. On one hand, it is clear that an auditor should not audit himself, but given the nature of the feedback, previous knowledge of the building is invaluable and this leads to encourage the virtues of a self-criticising practitioner (POE Forum 2002).

This paper takes on board the designers' responsibilities of reviewing the success of their building through the evaluation of three buildings in use designed by the same practice. The feedback lessons obtained thought the course of the study, are presented back to the architects and their opinion of the relevance of the lessons for future projects is evaluated by means of a questionnaire survey. Pointers are given to procedures throughout the building design and construction process to achieve smooth information loops that promote feedback, and ultimately improve building environments.

\section{Case studies - Methodology}

Three buildings are presented in this paper ${ }^{1}$, a glass museum (Figure 2 and 3) and two speculative offices (Figure 4). The designers had not made grand energy efficiency claims but implicitly they aspired to provide environmentally 
sensitive solutions. From such a starting point, groundbreaking energy performance was unlikely. The lessons obtained from the study should, however, be widely applicable to the practice's normally speculative projects.

For each case study, interviews with the designers provided information on the pre occupancy stages of the buildings. During informal interviews, designers were queried about Key Design Decisions, which in their opinion influenced the environmental performance of their buildings, together with the development of the project during construction and commissioning.

The post occupancy study compiled information on energy use, user comfort satisfaction and on actual conditions encountered. Available data included energy bills for a complete year, the Building Use Studies questionnaire survey ${ }^{2}$ (Leaman 2002), visual inspection during building visits (one in summer and one in winter) and monitoring of temperature, relative humidity and illuminance by means of $\mathrm{HOBO}^{3}$ data loggers in both summer and winter.

The lessons drawn from the pre and post occupancy studies were then fed back at a seminar, including the buildings' architects. Their judgement on the relevance and applicability of the feedback was recorded by means of a questionnaire.

\section{Preoccupancy - Design and construction.}

The museum key design decisions included the following:

- Differentiation between the exhibition "black" boxes and a glass square (Figure 5) 
- Use of thermally massive elements (bricks volumes and solid floor slabs) to even out temperature swings, and diverse glass facades to provide different solar control according to orientation.

- Aim to minimise air conditioning and provide controls for both natural and mechanical services by means of a Building Energy Management System.

- Promoting the use of local products throughout the construction process.

Some thermal modelling was carried out to determine the impact of solar gains through horizontal glazing in the glass square, around the brick boxes perimeter. The horizontal glazing was reduced to cover only the perimeter of the glass square. The exercise was not combined with any lighting assessment and no natural light reaches now the centre of the building.

During construction, the client decided that a carpet finish was to be added to the massive floor throughout. This decision will have an impact on the internal environment by decreasing the exposed thermal mass available and raising the air temperature of the interior.

Office1 was developed one year before Office2 for the same client. The same design team was retained for both offices. Their designs differ on the type of heating chosen (Office1 has a heat exchanger and traditional boilers, whereas Office2 uses condensing boilers), and the orientation of their entrances, which was governed by the approach to the site. Although both buildings were designed to be multi tenanted (figure 6), Office 2's main tenant was involved in the design process and continues to be closely engaged in the building management. In contrast, Office1 tenants were not involved on the design and leave all management to the landlord. 
The offices design focused on:

- The use of a rectangular shape to maximise the net to gross area ratio,

- The provision of an atrium mainly to introduce natural light into the interior of the buildings. Mechanical air extract from the offices discharges into the atrium and is taken out at plant room level.

- Careful orientation to face directly North South/East West and the provision of solar shading only to those areas that require it.

- Air supply and extract from the floor void to reduce section height. The chosen system allows a smaller floor to ceiling height than a fan coil system traditionally used in speculative developments at the time of design. The air-conditioning system chosen allowed three tiers of control: personal at the supply terminal device, local with the setting of zones, and general at the plant overall settings.

Fit out guides were prepared by the designers to convey to the prospective tenants the main design issues. However, these were not passed down to the tenants and hence the communication chain was broken.

\section{Post occupancy - Environmental feedback results.}

\section{Energy Consumption}

No specific energy targets had been set during the design of the three study buildings. This section compares their performance with published best practice guidance. For the museum, monitored energy consumption was compared with a 10 years old energy survey of museums (Oreszczyn et al,1994) and the Energy Efficiency Office (EEO) recommendations for Museums, Galleries, Libraries and Churches (DoE 1994). For the two offices, comparison was made 
with the latest versions of the Energy Consumption Guide 19 (DETR 2000) and the British Council of Offices Guide (BCO 2000).

The museum contained a glass furnace, in use throughout the year. The gas consumed annually by this activity was estimated to be $233 \mathrm{kWh} / \mathrm{m}^{2}$ from summer gas bills ${ }^{4}$. The furnace consumption has been separated in Figure 7 from the museum gas consumption without the furnace $\left(256 \mathrm{kWh} / \mathrm{m}^{2}\right)$. Figure 7 compares the monitored electricity and gas consumption with the EEO's yardsticks for high and low energy consuming museums. Both the museum's gas and electricity annual consumption figures are significantly above the EEO's recommendations (gas use $38 \%$ above, electricity $45 \%$ above).

Possible reasons for the high energy consumption include miscalculations on the allocation of gas use, particularly regarding the furnace, uncontrolled settings for heating/cooling, and energy inefficiency of the building with high heat losses through air leakiness and the building fabric.

In contrast, the cost of running the museum's energy bill $\left(£ 9.3 / \mathrm{m}^{2}\right.$ without the furnace or $£ 11.7 / \mathrm{m}^{2}$ including the furnace) does compare well with Oreszczyn et al (1994) survey of 43 museums with diverse servicing strategies $\left(£ 9.1 / \mathrm{m}^{2}\right.$ average cost for partial $\mathrm{a} / \mathrm{c}, £ 7 / \mathrm{m}^{2}$ average cost all types of servicing). At present, energy prices are low compared to the 1994 study and, for the average cost of a museum's energy expenditure ten years ago, in 2000 , a museum consumes more energy and has higher carbon emissions.

Figure 8 shows a comparison of the adjusted annual energy consumption ${ }^{5}$ of the two case study office buildings with both typical and good practice 
benchmarks for standard air-conditioned offices. The benchmark data was collected in the 1990s for the Department of the Environment Transport and the Regions. Typical values represent the median values of the database ${ }^{6}$ and good practice figures the lower quartile (DETR, 2000). If unadjusted energy use data is examined, Office 2 uses $16 \%$ more energy than Office1. However, Office2 has extended hours of operation (24hr in two zones) and intensive energy uses (dedicated computer room and catering kitchen areas) that are not present in Office1.

The adjusted data, figure 8, shows Office2 performing better than Office1 both in the use of electricity ( $7 \%$ below) and gas ( $42 \%$ below). Possible reasons for the difference in gas usage between the two offices include the choice of heating system, settings, and maintenance quality. Gas use for heating compares well with the benchmark in both buildings: Office1 $23 \%$ below typical use, and Office $218 \%$ below good practice. Electricity use is high in both buildings (Office1: 25\% above Typical, Office2: 16\% above Typical).

The energy metering in Office 1 could not split the energy consumption by tenancy or use. Office2, however, had separate meters identifying tenanted and common areas. Common areas use accounts for $40-45 \%$ of the total electricity consumption. Further assessment of electricity use in Office2, figure $9^{7}$, allocates large items of the central plant (chiller and pumps $-28 \%$ and $8 \%$ respectively of the total energy use) to the common areas. A clearer and more accurate understanding of the building's energy use would have been possible if large items of plant were metered separately.

Electricity use for lighting within Office2 can be marked as good practice ( $26 \mathrm{kWh} / \mathrm{m}^{2}$ for office lighting $\& 8 \mathrm{kWh} / \mathrm{m}^{2}$ for other lighting); this is due to the use of energy efficient luminaires, rather than to the effective use of daylighting or good control of artificial lighting. Further improvements in lighting electricity use are, therefore, possible. 


\section{Building in use}

At the end of the design and construction process, the buildings received reasonable critical acclaim from the architectural profession, the offices with regards to their design and construction process (Anon. 2000), and the museum in relation to its use of brickwork and glass (Dawson 2000, Gonzo and Vicari 2001), and lighting design (Sims 2000).

Post occupancy, the buildings' users ${ }^{8}$ were questioned in the winter of 2002 using the BUS questionnaire (BUS @ 2002 version) modified to include issues relevant to the museums rather than offices for which the questionnaire was originally designed (Carmona Andreu 2002).

The questions asked for the occupant's rating on a 7-point scale of various design and environmental parameters. Figures 10 to 15 present the mean responses for the monitored buildings. Responses to the environmental questions are compared with the BUS database benchmark and, in the Office2 case, with an exemplar building.

Results from the questionnaire surveys indicated that the users appreciated the overall building design and image - see Figures 10 and 11 . The great disappointment comes on the storage provision in the museum, which is considered very inadequate by the museum staff. The workshop areas facilities and the general use of space were also criticised.

The environmental performance of the case study buildings was compared with the BUS benchmark ${ }^{9}$, see figures $12,13,14 \& 15$.

The museum provides comfortable conditions overall and in terms of temperature and air quality, especially in winter. However, it presents problems with contrast glare from both natural and artificial lighting, see figure 16. Although the users perceived the level of controls over the various 
environmental variables as low, it seems to be the typical scenario as the comparison with the BUS benchmark indicates. However, the perceived control over ventilation and lighting was significantly lower.

Figure 17 shows the recorded light levels, through two cross sections of the buildings, during a summer visit under clear conditions at 14:00 to 15:00 (August 2001). Very low lighting levels can be noticed in the core of the building, which would explain the high contrast glare conditions witnessed. The original design intention was to include centrally located roof lights, but, as the design developed, these were omitted to avoid solar gains and reduce costs. The use of tools to predict daylight levels in the building during the design phase could have provided a clearer understanding of the design options.

The results from the Office 2 questionnaire survey suggest that this building is typical of air-conditioned buildings, with overall comfort variables around the BUS benchmark. For comparison with a salient building, data for the Elizabeth Fry building (Probe Team1998) ${ }^{10}$ has also been included on figures 14 and 15. Occupants' perception of the environmental controls is consistently below the BUS benchmark and they point towards the following vicious circle found in operating a system with poor controls. Both offices have Fan Tile Units (FTUs), see Figure 18, as terminal supply devices, which can provide a high degree of local environmental control. They are recessed on the floor void and under the personal control of the users. Both the temperature and velocity of the air supply can be altered but, the occupants get frustrated with the FTUs and switch them off; later on they forget they did so and complain of being either too hot or too cold. Figure 19 shows the instructions provided by the manufacturer to one of the tenants in Office1. Even with the instructions many occupants would be confused and subsequent discussion with the users of both offices 
suggest that the main mechanism for controlling these units was simply the clearly labelled on/off switch.

The designers' expectations in terms of the flexibility of conditions provided by the control system have not materialized at various levels. Not only do the occupants have problems controlling the system locally, but there have also been difficulties in fully commissioning the systems, as the control software for the plant room unit was not provided in full. Maintenance staff at Office1 still cannot alter the settings either for time or temperature, some four years after completion.

In both case study offices, electric lighting is controlled via remote controls at each column position. Occupants were however unhappy with this method of light switching because the control units would be frequently moved from the columns to people's desks. Each $9 \mathrm{~m}$ bay is switched independently. At the perimeter, this level of control is not sufficient as it results in lights being left on for users in the deeper zone, whilst there is more than sufficient daylight at the perimeter, see figure 20. Retrofitting controls is expensive and disruptive, whereas including separate perimeter switching during the building design stage, improves the energy efficiency of the installation at a small cost.

\section{Monitored environmental conditions}

Air temperature, relative humidity and light levels conditions were monitored in four locations in the museum and in two locations inside each of the office buildings for one month in summer and winter.

Internal conditions recorded in the museum were variable and follow regular patterns matching the cycles of both solar gains and internal heat gains. The 
exception being the air-conditioned exhibition space, where the temperature only varies by $\pm 5 \%$.

A large variation in relative humidity (25-30\% to $60-65 \%)$ was recorded both in the mechanically ventilated and the air-conditioned exhibition spaces, see figure 21 , whereas objects from a mixed collection on display ideally require a relative humidity of $40-60 \%$ (Blades 2002). Therefore conservation of the objects is heavily dependent on the environmental control provided by the display cases. The average temperatures logged at the office buildings stayed within the comfort set design conditions $\left(22^{\circ} \mathrm{C} \pm 2^{\circ} \mathrm{C}\right)$, and differences of internal conditions between the two buildings or the various tenancies resulted from the preferred conditioning settings entered at plant level.

\section{Feeding forward}

Results from the above case studies, with the following environmental lessons were presented back to the architects; some of the lessons were of a general nature whereas others referred more specifically to the building type.

\section{General lessons}

- "Good" design image does not equate to good environmental performance of buildings - The buildings scored well in the occupant surveys on design image, but presented problems with environmental issues.

- Aesthetic design decisions have complex environmental consequences that need to be understood - e.g. the choice of the "black box" strategy for the museum cuts off unwanted solar heat gains and sunlight on display objects, but it makes constant artificial lighting necessary which in turn increases cooling loads. 
- Design changes can have more than one environmental consequence and predictive computer simulations often focus on one aspect of design in detriment to others. For example, thermal performance models do not look at lighting levels. A holistic evaluation of environmental performance is therefore recommended.

- Complex control systems are difficult to use properly - the central management systems used complex software and user training was difficult. Simple local control systems also need to be fool proof and accessible, in order to avoid occupants resorting to simply using them as on-off controls.

- The success of the environmental design can depend on how the organisation occupying the building is managed. The style of management used influences the flow of information which can vary from the straightforward as in the Museum, to the over complex communication chain apparent in Office1. However, buildings are not designed with a specific management style in mind.

- In all three cases there was little follow through communication between designers and end users. For both offices, tenant fit out guides were prepared but the landlord did not pass them down to the tenants!

All three buildings used more energy than good practice levels. Design targets were not set, and, what's more, users did not set any consumption targets either, utilising whatever energy they "needed". In addition, low fuel pricing is no incentive for energy efficiency either. This raises the question of whether there is any real concern at all with energy efficiency within the construction industry, beyond meeting regulatory requirements.

\section{Lessons from the Museum study}


- Low temperatures in winter helped to keep the relative humidity high within the exhibition areas.

- There is no active relative humidity $(\mathrm{RH})$ control to overcome short time fluctuations in $\mathrm{RH}$ - exhibition cases are therefore required to provide $\mathrm{RH}$ stabilization, and any failure in their design or fit out will lead to instability. A more robust approach may use the building fabric to buffer conditions, and stabilise RH (Oreszczyn et al, 1994b).

- Lighting levels were low, but electricity consumption high, with lights on all the time. Increased electric lighting would reduce contrast glare but would further increase energy consumption. The full environmental implications of design changes, such the omission of rooflights, need to be predicted with confidence and communicated to clients.

- The Building Energy Management System (BEMS) is under utilised - no clear monitoring and targeting is currently in place. Control settings are not finetuned. The BEMS installers are more interested in setting up energy management contracts, and thus directly benefiting from the savings made by using the system properly, than providing training to the building users.

- Sub metering would help to quantify the energy cost of large consumers such as the furnace. It would also clarify the power used for ventilation and cooling and provide some markers for possible savings. And, it would allow the comparison of energy consumption by standard buildings services between museum buildings.

Published energy data for this type of building requires updating.

- Building design could have promoted energy efficiency further by carefully considering the insulation and thermal mass needs, thus minimising heat losses; and by setting close control of ventilation, avoiding clear air paths and ensuring an airtight construction. 
- Material detailing followed predominantly aesthetic rather than environmental reasons. The glass square corner details present a three-dimensional fine joint of three single glazed panes, exactly where heat losses are greatest. Such decisions might be justifiable on aesthetic grounds but the physical and environmental consequences are often not considered fully.

\section{Lessons from the Offices study}

- Metering the large energy consumers separately will help to monitor wasteful use and suggest possibilities for improvement. Large items of plant (chiller, pumps, boilers) are included in common metered areas. Time settings and controls remain within the control of the general building management. Tenants are charged proportionally to their rented areas not their demand. Hence, there is little motivation to reduce the energy cost. .

- Glare from both natural and artificial lighting led to a "lights on, blinds down" scenario.

- With the blinds up, lights were also found to remain on around the perimeter of the buildings, questioning the efficiency of the artificial lighting manual controls. A separate, daylight-linked automatic controlled perimeter zone, extending to a depth equal to floor-to-ceiling height, is proposed. Tenants are reluctant to retrofit additional zone controls and switches because of costs, whereas the cost of these controls would seem minimal if considered at the design stage.

- Remote control light switching proved unpopular because moveable controls positioned on columns went missing. .

- The potential flexibility of environmental control by the three-tiered air conditioning system has not yet materialised. This appears to result from lack of clarity at the commissioning stage, varying maintenance support and 
frustrating controls at point of use. Flexibility will be put to the test even further when fitting out for new tenants takes place.

- A clear method of communicating design intentions through a long chain of management is required. Designers cannot control the environmental performance of their buildings unless the users understand the modes of operation of the building. Possible methods include logbooks, as required by the new part L2 document (DoE 2000), and presentations by the designers, directly to the users, of the building operation strategies.

- Flexibility in the future with little control over the pattern of use, points towards the need of designing more robust buildings, capable of withstanding a greater variety of conditions. This is likely to be pushed more by strong design attitudes than lead by developer clients, but it certainly implies a general responsibility on the designer's side towards the use of energy within buildings and ultimately towards the sustainability of the environment.

\section{Architect's reception to the study}

The value of environmental feedback for architects was investigated during an in-house seminar held at the design office where the buildings were designed. At this seminar, the feedback lessons from the three case studies was presented. A questionnaire survey (Carmona Andreu 2002, Appendix A10) assessed the views of the audience on the following areas:

- $\quad$ The advantages and disadvantages of feedback

- $\quad$ The relevance of the information presented for their work

- $\quad$ Reasons for commissioning a feedback study

- The acceptable cost of feedback studies 
The questionnaire sample was small (20 attendees) but the response rate high $(85 \%)$

As attendance was voluntary, the attendees should be assumed to have been self-selecting and interested in the topic. Thus, $94 \%$ believed that feedback was necessary. More than half $(53 \%)$ believed there were no disadvantages to feedback; $30 \%$ however, mentioned time and cost as problems, and only $6 \%$ were worried that it might curtail design freedom.

Feedback advantages mentioned included improvement of future designs and informing new briefs, assessing building performance, getting user design input, and providing a basis for discussing comfort with clients at an early stage.

All the feedback lessons presented at the seminar were found to be relevant to the designers' work, with emphasis on the occupant comfort and energy use issues, followed by the key design decisions, see Figure 22. Management issues and considerations on the feedback process were found to be the least relevant.

Attendees were asked to rate, on a scale from 1 to 10 , a series of reasons for commissioning feedback and suggest any additional reasons not listed. Figure 23 shows the ratings in descending order of importance. Improving future briefs was rated as the most important reason, followed closely by improving design solutions and obtaining information on the sustainability/environmental performance of the project. Surprisingly providing good marketing and strengthening client relationship were considered less important reasons for feedback. This result is optimistic as it indicates that providing a product that performs well environmentally is important to designers. 
The questionnaire asked respondents to rate the cost, ease of justification and the value of feedback, if a typical survey of this type were to cost around $£ 10,000$ for a building which cost $£ 10$ million to build, i.e. $0.1 \%$ of construction cost (Bennetts1998), see Figure 24.

Although it was found that it would be money well spent and even on the low side, the expense does not seem easy to justify. The main drawback as pointed out by Cooper (2001) is one of ownership of the cost. When a feedback study is done two or three years down the line, the project budget is no longer available and, for designers, non-project allocated time is a clear overhead. Since the benefits are mostly for improved design and knowledge acquisition for new buildings, it should be possible to link this type of case studies to the beginning of projects rather than the end, with a clear perspective on closing the feedback loop and implementing its lessons.

\section{Feed forward process}

The link between each of the stages of a building life is a continuous line of communication, which includes all aspects of the building from the original design intention to construction anecdotes, to understanding the way the building is used and discovering lessons to be taken up by other projects, see figure 1.

Lawrence et al (1998) give a wide definition of feedback: "in its simplest form, feedback is a means of learning from experience by carrying out the processes of reflection and deduction". In the construction industry, a project based culture, lessons can be learned not only after completion of a project but throughout its development, forming a cycle of continuous improvement. 
Sharing knowledge is of paramount importance to achieve good quality buildings. Intranets and databases are becoming common practice in large architecture firms and in-house personal levels of expertise in concept design, technical (including environmental) matters and diverse building types are shared between projects. They form the infrastructure of a rich knowledge base for all to use. Workshops, at different stages of projects are used as means to discuss key issues, aims and aspirations. But there is little record of the decision-making process. Personal memories can be unreliable as they focus on individuals who do not always have continuous involvement in a project or process.

Guidance on the type of information to be collected, the methodology to be used and the appropriate time scales is required for feedback to be effective. Currently, the end of the defects liability period is seen as the most likely time such a study would take place, as designers need to revisit the building in any case. The first twelve months of operation has also been suggested as the time when some contractual obligation might be set to prove a building's performance (Jaunzens et al 2001).

\section{Conclusions}

This paper has highlighted lessons from feedback studies and fed them back to architects with encouraging results. They found the information presented relevant to their work. Their main interest in feedback was so that they could improve future briefs, achieving better design solutions and checking the sustainability of their designs. 
The case studies followed a preoccupancy versus post occupancy methodology. For the preoccupancy study data was gathered from interviews with designers (both architects and engineers) and project documentation. The post occupancy evaluation consisted of an energy use check, building visits, occupant questionnaire survey and temperature and humidity conditions monitoring.

The success of any feedback study relies on the quality of data gathered. With a view to carrying out objective feedback in future, briefs should mention not only spatial design aspirations, but also:

- energy targets - split by fuel type- ,

- management structures expected in operating the building,

- degree of control and automatism,

- information requirements at different stages - from simulations, to commissioning and building logbook,

- the requirement for feedback itself.

For the decision-making stages, it would be preferable to record design intentions and expected performance of systems specified, and to monitor any changes of the design or construction.

The study showed that design decisions have an impact on the environmental performance of buildings, but their consequences are not necessarily considered fully during the project development. This results in missed opportunities (e.g. using the fabric in the museum to provide a better environmental control layer) or design changes (e.g. increased plan depth without natural daylight) that reduce the energy efficiency of buildings. Advise on environmental issues seems therefore relevant throughout the whole project, from the very first design concept to final commissioning, and beyond into the building's life in use, when the actual performance efficiency becomes apparent. Architects need to either increase their awareness on such issues themselves, or seek expert advice as early as possible. Most significantly, 
architects will lack confidence of providing sustainable solutions if no practical corroboration can be made of their sustainability claims.

Figure 25 proposes a continuous loop of activities to take place at each stage to promote ever-improving solutions. It starts with a feedback study of the type carried out for the case studies presented here. In brackets key participants are highlighted $(\mathrm{De}=$ designer, reflecting the person(s) within the firm in charge of the project; $\operatorname{Exp}=$ expert person(s) on the building type or technology; $\mathrm{Cl}=$ client; $\mathrm{U}=$ building user). The letters inside the circles refer to RIBA Plan of Work stages ${ }^{11}$.

The success of any such continuous improvement programme relies on its capability to maintain the level of interest of all the participants on the process. As Bordass et al (2001) put it: "from the client elaborating the brief to sustained management in use, a successful building needs the interest and the dedication of all the participants in the development". For architects, this equates to recording the decisions they make clearly and a willingness to know the consequences of such decisions in practice.

\section{Acknowledgements}

Originally, much of this work was undertaken as part of a MSc in Environmental Design and Engineering at the Bartlett School of Graduate Studies, University College London.

This piece of work could not have been produced without the support of Reid Architecture and the help of the owners, designers and users of the museum and the offices. Sincere gratitude goes to all of them.

\section{References}

Anon. (2000), Project 101, BAA Lynton roll out Mark 3, M4, May 
Bennetts R. (1998), 0.1\% for Feedback, posted on www.usablebuildings.co.uk, based on keynote address, Intelligent Buildings conference, BRE, October

Blades N. (2002) Course notes Master on Environmental Design and Engineering, University College London, London

Bordass B., Leaman A. and Ruyssevelt P. (2001), Assessing building performance in use 5: conclusions and implications, Building Research and Information 29(2), 144-157

British Council for Offices (2000), BCO Guide 2000, Best practice in the Specification for Offices, $3^{\text {rd }}$ Edition, June

Building Research and Information (2001a) 29 (2)

Building Research and Information (2001b) 29(6)

Building Research and Information (2002) 30 (1)

Carmona Andreu I (2002), Environmental Feedback: A case study approach, MSc Environmental Design and Engineering, University College London

Cohen R., Standeven M., Bordass B. and Leaman A. (2001), Assessing building performance in use 1: the Probe process, Building Research and Information 29(2), 85-102. 
Cooper I. (2001), Post occupancy evaluation - where are you? Building Research and Information 29(2), 158-163

Dawson S (2000),, Glass of its own, AJ building study, the architects' journal, $5^{\text {th }}$ October $28-37$

Department of the Environment (1994), Energy Efficiency Office, Introduction to Energy Efficiency in Museums, Galleries, Libraries and Churches, Best Practice Programme

Department of the Environment Transport and the Regions (2000), Energy Efficiency Best Practice Programme, Energy Consumption Guide 19, Energy use in offices, BRECSU for DETR, Watford December

Department of the Environment and The Welsh Office (2002), The Building Regulations 2000, Approved Document L2, Conservation of fuel and power, HMSO

Field J. et al (1998) CIBSE Technical Memorandum: Energy Assessment Reporting Methodology. Office Assessment Method.

Gonzo E, Vicari A (2001), World of Glass, St Helens on Merseyside, Progetti, Costruire in Laterizio 84, Novembre/Dicembre, 16-21

Halliday S. (2000), Green Guide to the Architect's Job Book, RIBA Publications, London 
Jaunzens D., Hadi M., Graves H. (2001), Encouraging Post Occupancy Evaluation DTI Report 200670, CRISP Commission 00/12, Environment Division, Building Research Establishment, Garston, October

Lawrence Race,G., Pearson, C., de Saulles T (1998), Feedback for better building services design, Application Guide AG21/98 , BSRIA, London

Leaman A. and Bordass B. (2001), Assessing building performance in use 4: the Probe occupant surveys and their implications, Building Research and Information 29(2), 129-143

Leaman A (2002), Building Use Studies questionnaire @ 2002, available under licence from www.usablebuildings.co.uk.

Lupton S. editor (2000), Architect's Job Book $7^{\text {th }}$ Edition, RIBA Publications, London

Oreszczyn T., Mullany T., Ni Riain C. (1994a), A survey of Energy use in Museums and Galleries, Museum Environment Energy, Museums and Galleries Commission, May Cassar editor, HMSO, London

Oreszczyn T., Cassar M. and Fernandez K, (1994b) Comparative study of airconditioned museums, Preprints of the Contributions to the Ottawa Congress, 12-16 September, Preventive Conservation Practice, Theory and Research, Edited by Ashok Roy and Smith Perry, London, 144-148

Post Occupancy Evaluation Forum (2002) organised by Building Research Establisment, 25th July, RIBA, London. Participants included amongst others: 
Alistair Blyth, Bill Bordass, Derek Clements-Croome, Ian Cooper, Joanna Ely, Max Fordham, Mindy Hadi, Denice Jaunzens, Robin Nicholson, Jim Ure.

Probe Team (1998), Probe 14: Elizabeth Fry Building, Building Services Journal, CIBSE, London, April

RIBA Publications (1999), Standard Form of Agreement for the Appointment of an Architect (SFA/99), RIBA, London

RIBA Publications (2000), Plan of Work, RIBA, London

Sims B, World of Glass, Light and Lighting, August - September (2000), 10-12

Whyte J, Gann D M (2001), Closing the loop between design and use: post occupancy evaluation, Building Research and Information, 29 (6), 460-462 


\section{ENDNOTES}

${ }^{1}$ The case study buildings by Reid Architecture had been in use for at least two years. All the data was collected as part of an MSc dissertation project (Carmona Andreu 2002).

${ }^{2}$ Building Use Studies questionnaire (c) 2002 was used, and it is available under licence from www.usablebuildings.co.uk

${ }^{3}$ HOBO H8 Family of data loggers - http://www.onsetcomp.com

${ }^{4}$ Summer time monthly gas consumption of museum $=83,333 \mathrm{kWh}$.

Estimated glass furnace annual gas consumption $/ \mathrm{m}^{2}=83,333 \mathrm{kWh} / \mathrm{month} \times 12$ months $/ 4,286 \mathrm{~m}^{2}$ (TFA museum) $=233.32 \mathrm{kWh} / \mathrm{m}^{2}$ year

${ }^{5}$ Offices data has been adjusted to account for weather, occupancy and special uses (computer room and catering) following the Energy Assessment Reporting Methodology (EARM) Stage 2 described in CIBSE Technical Manual 22 (Field et al, 1998).

${ }^{6}$ The ECON 19 (2000) database contains data from 200 office buildings and includes both refurbished and new built offices.

${ }^{7}$ Further analysis followed EARM Stage 3, assessing electricity use from specification, drawings and observation during the building visit; but no reconciliation was possible with typical day and night demands. Typical annual equivalent hours of full load operation have been taken as 1000 hours for chillers and 3700 hours for pumps (DETR, 2002 - ADL2 Appendix G)

${ }^{8}$ Questionnaires were distributed amongst all regular users of the buildings, which in the case of the museum excludes visitors.

${ }^{9}$ The BUS benchmark gives the mean of the last 50 buildings, which have been surveyed using the questionnaire, e.g. PROBE building studies, and therefore gives a comparison with "typical" buildings.

${ }^{10}$ Although E Fry is not an office building, the published BUS survey on the E Fry PROBE, concentrated on the office staff responses which are therefore comparable to the BUS benchmark (Probe Team1998).

${ }^{11}$ Stage M (Feedback) is no longer described in the RIBA Plan of Work 2000 or the Standard Form of Agreement for the Appointment of an Architect (1999), but it is described in the Architect's Job Book (2000). Feedback activities are discussed on the Green Guide to the Architects' Job book (Halliday, 2000) under stage L. 